\title{
Development of a New Multifunctional Cationic Surfactant System with Corrosion Inhibiting Ability
}

\author{
Erdong Yao, Tianbo Liang, Yuan Li, Jiaxin Sun, and Fujian Zhou \\ The Unconventional Natural Gas Institute, State Key Laboratory of Petroleum Resource and Prospecting, \\ China University of Petroleum, Beijing 102249, China \\ Correspondence should be addressed to Fujian Zhou; zhoufj@cup.edu.cn
}

Received 31 May 2017; Revised 31 July 2017; Accepted 8 August 2017; Published 19 September 2017

Academic Editor: Zhien Zhang

Copyright (C) 2017 Erdong Yao et al. This is an open access article distributed under the Creative Commons Attribution License, which permits unrestricted use, distribution, and reproduction in any medium, provided the original work is properly cited.

Four alkyl propargyl bis(hydroxyethyl) ammonium surfactants with different lengths in hydrophobic tail (C8-C16) are prepared by direct alkylation of diethanolamine with alkyl bromides. The surfactants exhibit excellent surface properties. The critical micelle concentration (CMC) values of the surfactants $2 \mathbf{c}$ and $2 \mathbf{d}$ are found to be $7.63 \times 10^{-4}$ and $1.23 \times 10^{-4} \mathrm{~mol} / \mathrm{L}$, and the corresponding surface tension $\left(\gamma_{\mathrm{CMC}}\right)$ values are 31.83 and $31.69 \mathrm{mN} / \mathrm{m}$, respectively. Furthermore, all of the synthesized propargyl quaternary ammonium salts are found to be very effective in inhibiting the corrosion of N80 steel (IE\% = 92-98\%). They can be used at a relatively high temperature $\left(\geq 90^{\circ} \mathrm{C}\right)$ and a low concentration $(0.039 \mathrm{wt} . \%)$. In addition, the apparent viscosity of surfactant 2d is studied at various temperatures, and it can be used as a viscoelastic surfactant up to $100^{\circ} \mathrm{C}$. The synthesized surfactants possess multiple functions and have a very good compatibility with VES systems. They can be potentially used in various oil field applications such as enhanced oil recovery, fracturing, acid diversion, and well stimulation.

\section{Introduction}

Acidizing is a widely established technique to increase hydrocarbon production from low-permeability reservoirs [1]. Viscoelastic surfactant (VES) based diverting systems have many advantages that make them preferred for well acid stimulation mainly due to their exceptional rheological characteristics [2]. These systems leave no residues once broken and thus eliminate potential damage to the formation $[3,4]$. They also have abilities to minimize the fracture height growth and increase the effective fracture length [5]. However, VES systems frequently encounter considerable difficulties in corrosion inhibitors (CIs) selection. In many cases, corrosion inhibitors would break these VES gels, and this is because inhibitors usually have oil-soluble constituents (e.g., acetylenic alcohol) or contain mutual solvents (e.g., ethylene gylcol monobutyl ether) [6]. Such a conflict encourages us to look for new corrosion chemicals which will have a very good compatibility with VES systems.

A variety of organic compounds can act as CIs during the acidization, including acetylenic alcohols, aromatic aldehydes, amines, nitrogen-containing heterocycles, and quinoline derivatives [7]. Among them, acetylenic alcohols are widely used because of their commercial availability and cost effectiveness. Propargyl alcohol is usually taken as a standard CI for acidization and sometimes it has a significant synergistic effect with other compounds [8]. It is claimed to form a film on the metal surface and can retard the metal dissolution process as well as hydrogen evolution [9]. However, it has been reported that only propargyl alcohol has a good solubility in acids, while the dissolvability of other acetylenic alcohols decreases rapidly with increasing carbon chain lengths. To increase the solubility of such acetylenic alcohols, quaternary ammonium surfactants need to be applied [9]. In addition, many countries have banned them from use because of their toxicity [7]. Therefore, it is important to find water-soluble and nontoxic alternatives to acetylenic alcohols.

In this study, we developed a series of alkyl propargyl bis(hydroxyethyl) quaternary ammonium bromides with different hydrophobic lengths. By introducing propargyl group into quaternary ammonium surfactants, these compounds obtain a good corrosion inhibition ability and a good solubility in water/acid solution. Moreover, the compounds themselves are surface-active substances. When the carbon chain 

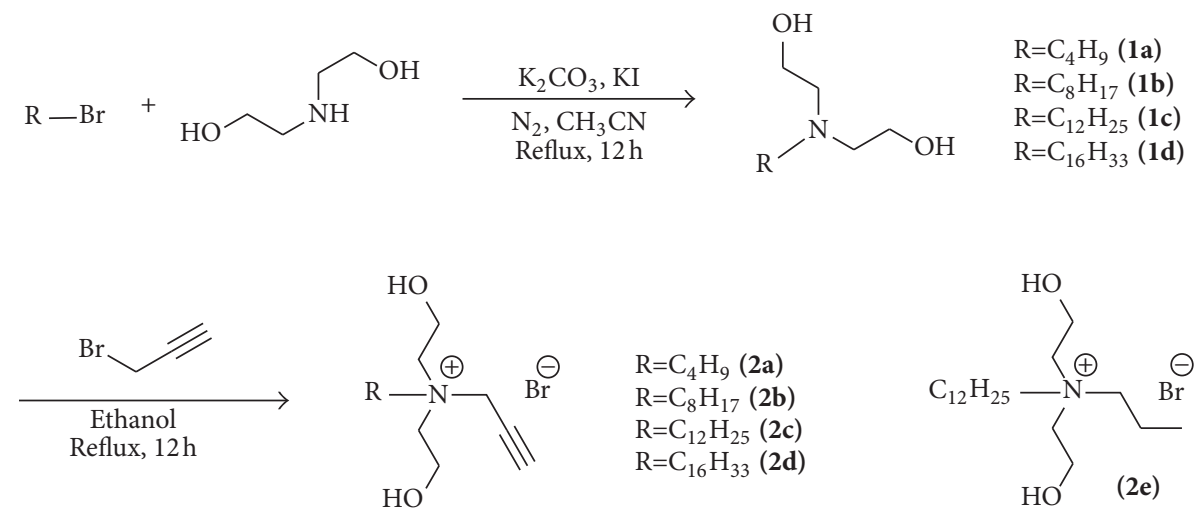

SCHEME 1: Synthesis of propargyl quaternary ammonium surfactants 2a-2d.

length of hydrophobic group is greater than 12 , the solutions exhibit high viscosities and/or gel-like behavior at room temperature in the presence of sodium salicylate (NaSal); they still retain appreciable viscosities at a temperature above $90^{\circ} \mathrm{C}$.

\section{Experimental Procedure}

2.1. Materials (Chemical Reagents, Solution Preparation, and Specimens). Distilled water was used as the solvent for all testing experiments. N-Alkyl bromide (Alfa Aesar, $\geq 99 \%$, GC), diethanol amine (Alfa Aesar, $\geq 99 \%$, GC), and propargyl bromide (Alfa Aesar, $\geq 99 \%$, GC) were used without further purification. All other chemicals with analytical grade were purchased from Sinopharm Group Beijing Co., Ltd., China.

The viscoelastic surfactant solution for rheological test consists of $4.0 \mathrm{~g}$ surfactant $2 \mathrm{~d}, 0.36 \mathrm{~g} \mathrm{NaSal}$, and $96.0 \mathrm{~g}$ water. The weight loss experimental tests were performed in $20 \mathrm{wt}$.\% hydrochloric acid solutions, which were prepared by diluting 36-38 wt. $\% \mathrm{HCl}$ with distilled water. The specimens were prepared from N80 steel. The dimensions of the N80 specimens for the weight loss experiments were $50 \times 10 \times$ $3 \mathrm{~mm}$. Before the experiments, the surface of the specimens was abraded with 2000 grit emery paper, followed by washing with distilled water, and degreased with ethanol and acetone. The specimens were finally dried at room temperature and stored in a desiccator.

2.2. Surface Tension. Surface tensions were measured at $20^{\circ} \mathrm{C}$ using a duNouy tensiometer. All surface tension measurements of the synthesized surfactants were conducted using distilled water as the solvent at mass concentration from $0.0001 \mathrm{wt} . \%$ to $1 \mathrm{wt} . \%$. All the reported data points were average equilibrium values.

2.3. Rheology Measurement. The apparent viscosity of surfactant was measured using a HAAKE MARS III Rheometer (Haake Technik Co., Germany) with the cylinder rotor DG41. In this study, the viscosity was reported under a temperature sweep range of 20 to $100^{\circ} \mathrm{C}$ at a steady shear rate of $170 \mathrm{~s}^{-1}$.
2.4. Weight Loss Measurement. N80 steel specimen was immersed in $20 \mathrm{wt} . \% \mathrm{HCl}$ solutions in the absence or presence of different concentrations of propargyl quaternary ammonium bromide for $4 \mathrm{~h}$ at 60 or $90^{\circ} \mathrm{C}$, in which the ratio of volume $(\mathrm{mL})$ of $\mathrm{HCl}$ solutions to surface area $\left(\mathrm{cm}^{2}\right)$ of the specimens was $20: 1$. The specimens were taken out, washed with ethanol and acetone in turn, dried, and weighed accurately. Two specimens were used in each test, and the mean value of corrosion rate was calculated. The corrosion rate of each specimen was calculated as the equation below:

$$
V_{\text {corr }}=\frac{W_{1}-W_{2}}{S \times t},
$$

where $V_{\text {corr }}\left(\mathrm{g} \mathrm{m}^{-2} \mathrm{~h}^{-1}\right)$ is the corrosion rate and $W_{1}(\mathrm{~g})$ and $W_{2}(\mathrm{~g})$ are the weights of a specimen before and after the $4 \mathrm{~h}$ experiment, respectively. $S\left(\mathrm{~m}^{2}\right)$ is the surface area of the specimen, and $t(\mathrm{~h})$ is the immersion time.

2.5. Synthesis of Propargyl Quaternary Ammonium Surfactants. Four alkyl propargyl bis(hydroxyethyl) ammonium surfactants (Scheme 1) were designed to check the influence of structural parameters. They varied in lengths in hydrophobic tail from $\mathrm{C} 4$ to $\mathrm{C} 16$, respectively. 1a-1d were synthesized using a modified procedure reported by Dan and Ghosh [10], and $\mathbf{2 a - 2 d}$ were prepared using a similar procedure reported by $\mathrm{Ge}$ et al. [11]. Moreover, a similar structure C12 surfactant $2 \mathbf{e}$ was selected as reference for corrosion testing.

Synthesis of N-Butyl-N-propargyl-N,N-bis(hydroxyethyl) Ammonium Bromide (2a). n-Butyl bromide (2.1 g, $0.015 \mathrm{~mol}$ ), diethanolamine ( $2.4 \mathrm{~g}, 0.023 \mathrm{~mol}$ ), anhydrous potassium carbonate $(4.28 \mathrm{~g}, 0.031 \mathrm{~mol})$, and potassium iodide $(0.5 \mathrm{~g})$ were taken in $40 \mathrm{~mL}$ acetonitrile and the contents were refluxed at $60^{\circ} \mathrm{C}$ under $\mathrm{N}_{2}$ atmosphere for $12 \mathrm{~h}$. The heating was stopped and the acetonitrile was evaporated and then $\mathrm{CH}_{2} \mathrm{Cl}_{2}$ $(30 \mathrm{~mL})$ was added to the reaction mixture. The solution was washed with $\mathrm{H}_{2} \mathrm{O}(3 \times 30 \mathrm{~mL})$ to remove the excess diethanolamine and then the organic part was dried over anhydrous $\mathrm{Na}_{2} \mathrm{SO}_{4} \cdot \mathrm{CH}_{2} \mathrm{Cl}_{2}$ was removed under reduced pressure to get the crude product la as colorless oil in $66.8 \%$ 


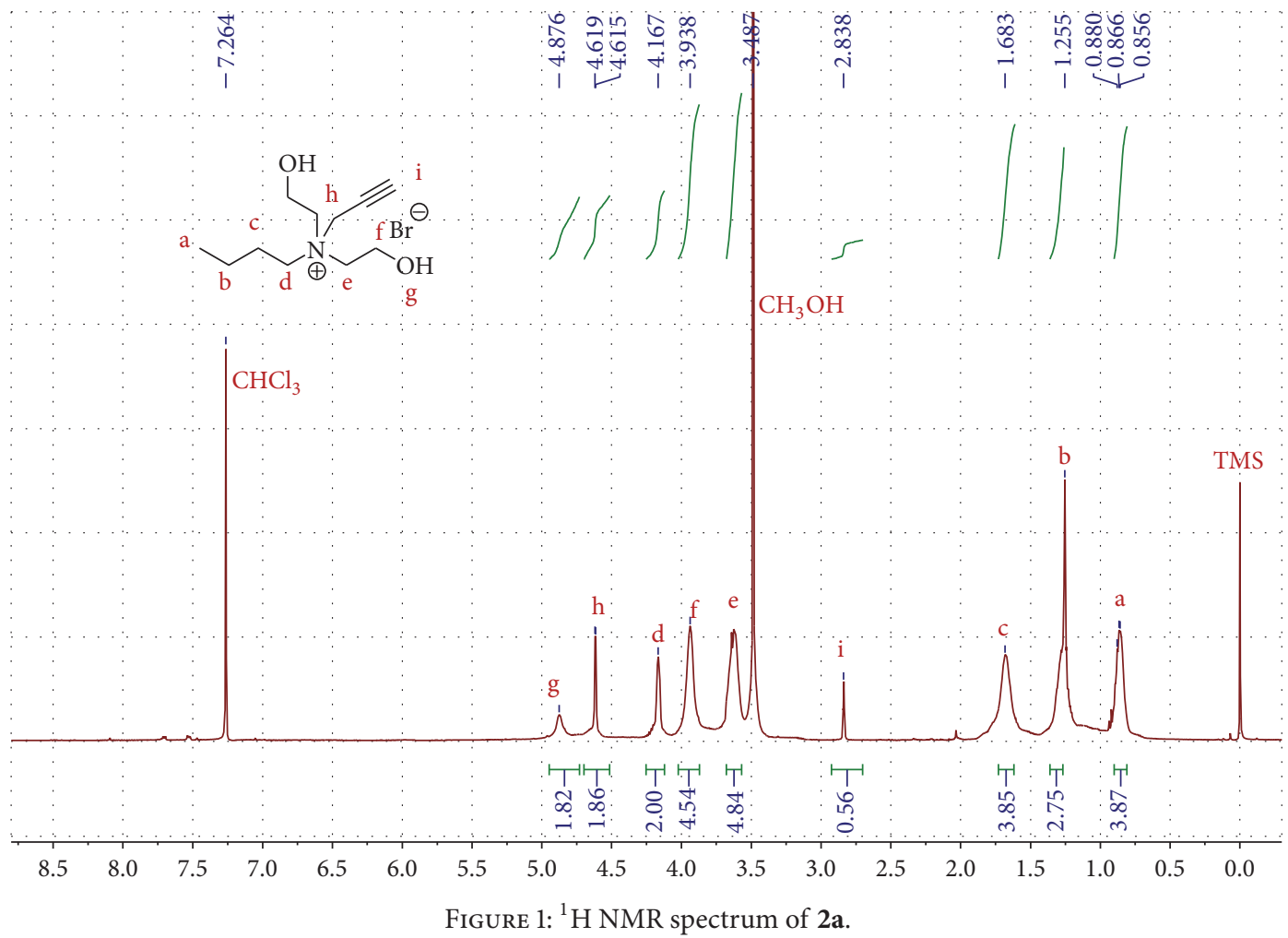

yield. As the product was found to be pure from TLC and ${ }^{1} \mathrm{H}$ NMR, no further purification was carried out at this stage. Then, compound la $(3.23 \mathrm{~g}, 0.02 \mathrm{~mol})$ was added to $100 \mathrm{~mL}$ solution of propargyl bromide $(3.1 \mathrm{~g}, 0.026 \mathrm{~mol})$ in ethanol. The mixture was refluxed for $12 \mathrm{~h}$. The solvent and the excess propargyl bromide were removed at room temperature under reduced pressure, and a red viscous liquid was obtained. The crude product was then purified by column chromatography (silica gel; methanol/ $\mathrm{CH}_{2} \mathrm{Cl}_{2}=1: 10$ ) to afford pure product (81.4\%) as a yellow oil. ${ }^{1} \mathrm{H}$ NMR $\left(\mathrm{CDCl}_{3}, 500 \mathrm{MHz}\right): \delta(\mathrm{ppm})$ $=4.93(\mathrm{~s}, 2 \mathrm{H},-\mathrm{OH}), 4.60\left(\mathrm{~d}, 2 \mathrm{H}, J=2.0 \mathrm{~Hz}, \mathrm{CH}_{2} \mathrm{C} \equiv \mathrm{CH}\right), 4.13$ (m, $\left.4 \mathrm{H}, \mathrm{CH}_{2} \mathrm{OH}\right), 3.79\left(\mathrm{~m}, 4 \mathrm{H}, \mathrm{CH}_{2} \mathrm{CH}_{2} \mathrm{OH}\right), 3.61(\mathrm{t}, 2 \mathrm{H}, \mathrm{J}=$ $\left.8.0 \mathrm{~Hz}, \mathrm{RCH}_{2} \mathrm{~N}\right), 3.09(\mathrm{t}, 1 \mathrm{H}, J=2.0 \mathrm{~Hz}, \mathrm{C} \equiv \mathrm{CH}), 1.81(\mathrm{~m}, 2 \mathrm{H}$, $\left.\mathrm{RCH}_{2} \mathrm{CH}_{2} \mathrm{~N}\right), 1.26\left(\mathrm{~m}, 2 \mathrm{H},-\left(\mathrm{CH}_{2}\right)-\right), 0.88(\mathrm{t}, 3 \mathrm{H}, J=7.0 \mathrm{~Hz}$, $\left.-\mathrm{CH}_{3}\right)$.

Compound $\mathbf{2 b}$. It was prepared following the same procedure of $2 \mathrm{a}$. Yield $=86.2 \%,{ }^{1} \mathrm{H}$ NMR $\left(\mathrm{CDCl}_{3}, 500 \mathrm{MHz}\right): \delta(\mathrm{ppm})$ $=4.93(\mathrm{~s}, 2 \mathrm{H},-\mathrm{OH}), 4.60\left(\mathrm{~d}, 2 \mathrm{H}, J=2.0 \mathrm{~Hz}, \mathrm{CH}_{2} \mathrm{C} \equiv \mathrm{CH}\right), 4.13$ $\left(\mathrm{m}, 4 \mathrm{H}, \mathrm{CH}_{2} \mathrm{OH}\right), 3.79\left(\mathrm{~m}, 4 \mathrm{H}, \mathrm{CH}_{2} \mathrm{CH}_{2} \mathrm{OH}\right), 3.61(\mathrm{t}, 2 \mathrm{H}, J$ $\left.=8.0 \mathrm{~Hz}, \mathrm{RCH}_{2} \mathrm{~N}\right), 3.09(\mathrm{t}, 1 \mathrm{H}, J=2.0 \mathrm{~Hz}, \mathrm{C} \equiv \mathrm{CH}), 1.81(\mathrm{~m}$, $\left.2 \mathrm{H}, \mathrm{RCH}_{2} \mathrm{CH}_{2} \mathrm{~N}\right), 1.37-1.28\left(\mathrm{~m}, 10 \mathrm{H},-\left(\mathrm{CH}_{2}\right)-\right), 0.88(\mathrm{t}, 3 \mathrm{H}, \mathrm{J}$ $\left.=7.0 \mathrm{~Hz},-\mathrm{CH}_{3}\right)$.

Compound $2 c$. It was prepared following the same procedure of 2a. Yield $=99.0 \%,{ }^{1} \mathrm{H}$ NMR $\left(\mathrm{CDCl}_{3}, 500 \mathrm{MHz}\right): \delta(\mathrm{ppm})$ $=4.93(\mathrm{~s}, 2 \mathrm{H},-\mathrm{OH}), 4.59\left(\mathrm{~d}, J=2.0 \mathrm{~Hz}, 2 \mathrm{H}, \mathrm{CH}_{2} \mathrm{C} \equiv \mathrm{CH}\right), 4.14$ (m, $\left.4 \mathrm{H}, \mathrm{CH}_{2} \mathrm{OH}\right), 3.80\left(\mathrm{~m}, 4 \mathrm{H}, \mathrm{CH}_{2} \mathrm{CH}_{2} \mathrm{OH}\right), 3.60$ (t, $2 \mathrm{H}, \mathrm{J}$ $\left.=8.0 \mathrm{~Hz}, \mathrm{RCH}_{2} \mathrm{~N}\right), 3.05(\mathrm{t}, 1 \mathrm{H}, J=2.0 \mathrm{~Hz}, \mathrm{C} \equiv \mathrm{CH}), 1.80(\mathrm{~m}$, $\left.2 \mathrm{H}, \mathrm{RCH}_{2} \mathrm{CH}_{2} \mathrm{~N}\right), 1.36-1.26\left(\mathrm{~m}, 18 \mathrm{H},-\left(\mathrm{CH}_{2}\right)-\right), 0.88(\mathrm{t}, 3 \mathrm{H}, \mathrm{J}$ $=7.0 \mathrm{~Hz},-\mathrm{CH}_{3}$ ).
Compound $2 \boldsymbol{d}$. It was prepared following the same procedure of 2a. Yield $=99.9 \%,{ }^{1} \mathrm{H}$ NMR $\left(\mathrm{CDCl}_{3}, 500 \mathrm{MHz}\right): \delta(\mathrm{ppm})$ $=4.89(\mathrm{~s}, 2 \mathrm{H},-\mathrm{OH}), 4.62\left(\mathrm{~d}, 2 \mathrm{H}, J=2.0 \mathrm{~Hz}, \mathrm{CH}_{2} \mathrm{C} \equiv \mathrm{CH}\right), 4.14$ (m, $\left.4 \mathrm{H}, \mathrm{CH}_{2} \mathrm{OH}\right), 3.82\left(\mathrm{~m}, 4 \mathrm{H}, \mathrm{CH}_{2} \mathrm{CH}_{2} \mathrm{OH}\right), 3.62(\mathrm{t}, 2 \mathrm{H}, \mathrm{J}$ $\left.=8.0 \mathrm{~Hz}, \mathrm{RCH}_{2} \mathrm{~N}\right), 3.05(\mathrm{t}, 1 \mathrm{H}, J=2.0 \mathrm{~Hz}, \mathrm{C} \equiv \mathrm{CH}), 1.80(\mathrm{~m}$, $\left.2 \mathrm{H}, \mathrm{RCH}_{2} \mathrm{CH}_{2} \mathrm{~N}\right), 1.37-1.26\left(\mathrm{~m}, 26 \mathrm{H},-\left(\mathrm{CH}_{2}\right)-\right), 0.88(\mathrm{t}, 3 \mathrm{H}, \mathrm{J}$ $\left.=7.0 \mathrm{~Hz},-\mathrm{CH}_{3}\right)$.

\section{Results and Discussion}

The quaternary ammonium surfactants $(\mathbf{2 a}-\mathbf{2 d})$ were synthesized as outlined in Scheme 1. N-Alkylation of diethanolamine with commercially available alkyl bromide produced the corresponding intermediates (1a-1d); with addition of propargyl bromide, it produced the required quaternary surfactants (2a-2d) with high yield. The chemical structures of all the synthesized surfactants were characterized with the aid of ${ }^{1} \mathrm{H}$ NMR as shown in Figures $1-4$. In the ${ }^{1} \mathrm{H}$ NMR of compounds $\mathbf{2 b}$, the alkynyl proton appeared at $\delta 3.09$ [$\mathrm{C} \equiv \mathrm{C}-\mathrm{H}]$ and the methylene protons $\left[-\left(\mathrm{CH}_{2}\right) n-\right]$ appeared at $\delta 1.37-1.28$ (Figure 2). The peaks of methylene protons [HO$\left.\mathrm{CH}_{2}-\mathrm{CH}_{2}-\mathrm{N}-\right]$ of hydroxyethyl group are $\delta 2.65$ and $\delta 3.61$ in $\mathbf{1 b}$ [10], and then clear downfield shift ( $\delta 4.13$ and $\delta 3.79$ ) of these protons $\left[\mathrm{HO}-\mathrm{CH}_{2}-\mathrm{CH}_{2}-\mathrm{N}-\right]$ in $\mathbf{2 b}$ confirmed the formation of the quaternized product [12]. Spectra of $\mathbf{2 a}, \mathbf{2 c}$, and $\mathbf{2 d}$ look very similar to $\mathbf{2 b}$ in peak positions and patterns except different methylene protons peaks $\left[-\left(\mathrm{CH}_{2}\right) n\right.$ - $]$ at $\delta$ $1.37-1.28$, which indicates they are the homologs.

3.1. Surface Tension Measurements. All surfactants $\mathbf{2 a - 2 b}$ have good solubility in water, which will have a very good 


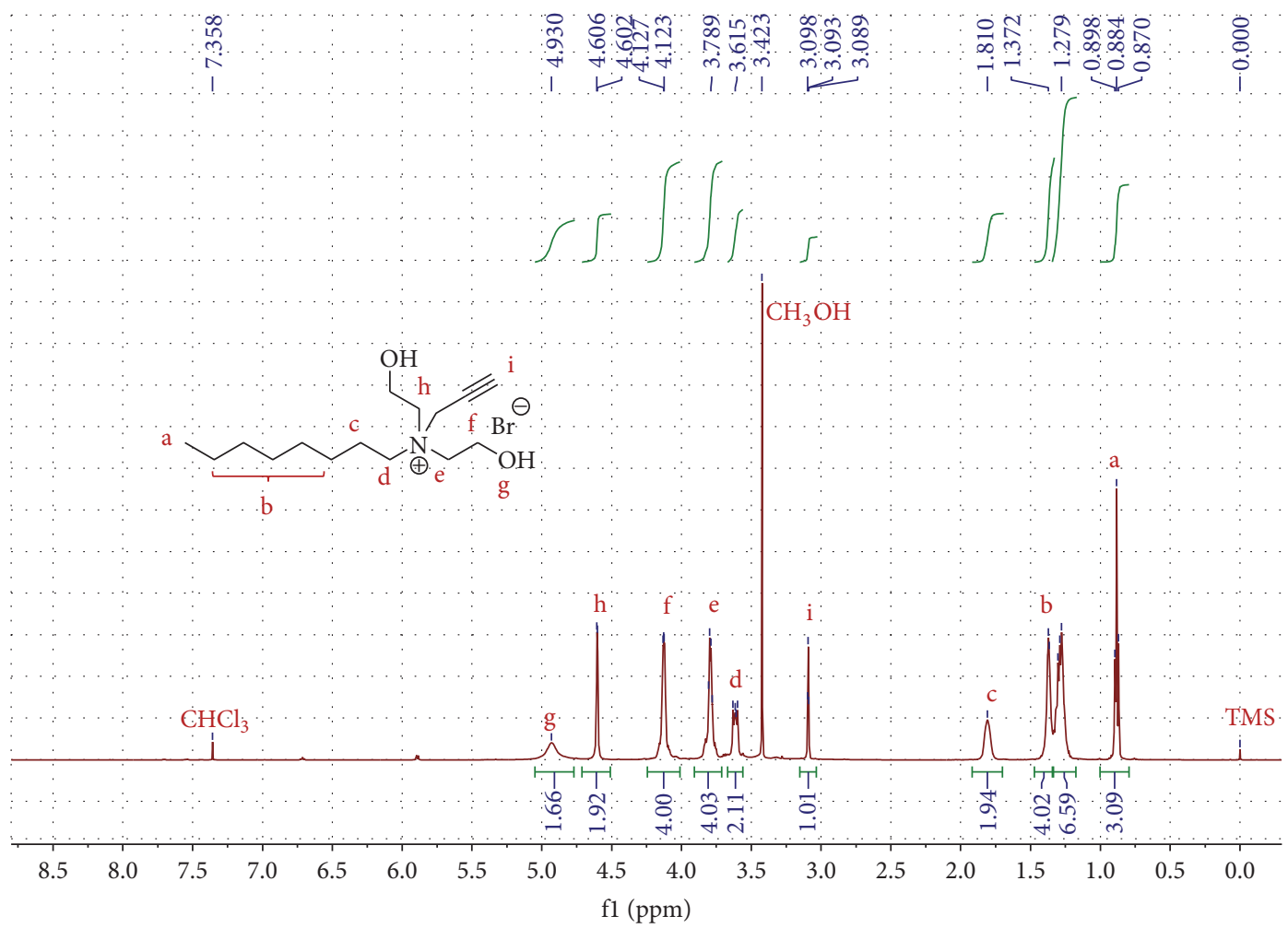

FIgURE 2: ${ }^{1} \mathrm{H}$ NMR spectrum of $\mathbf{2} \mathbf{b}$.

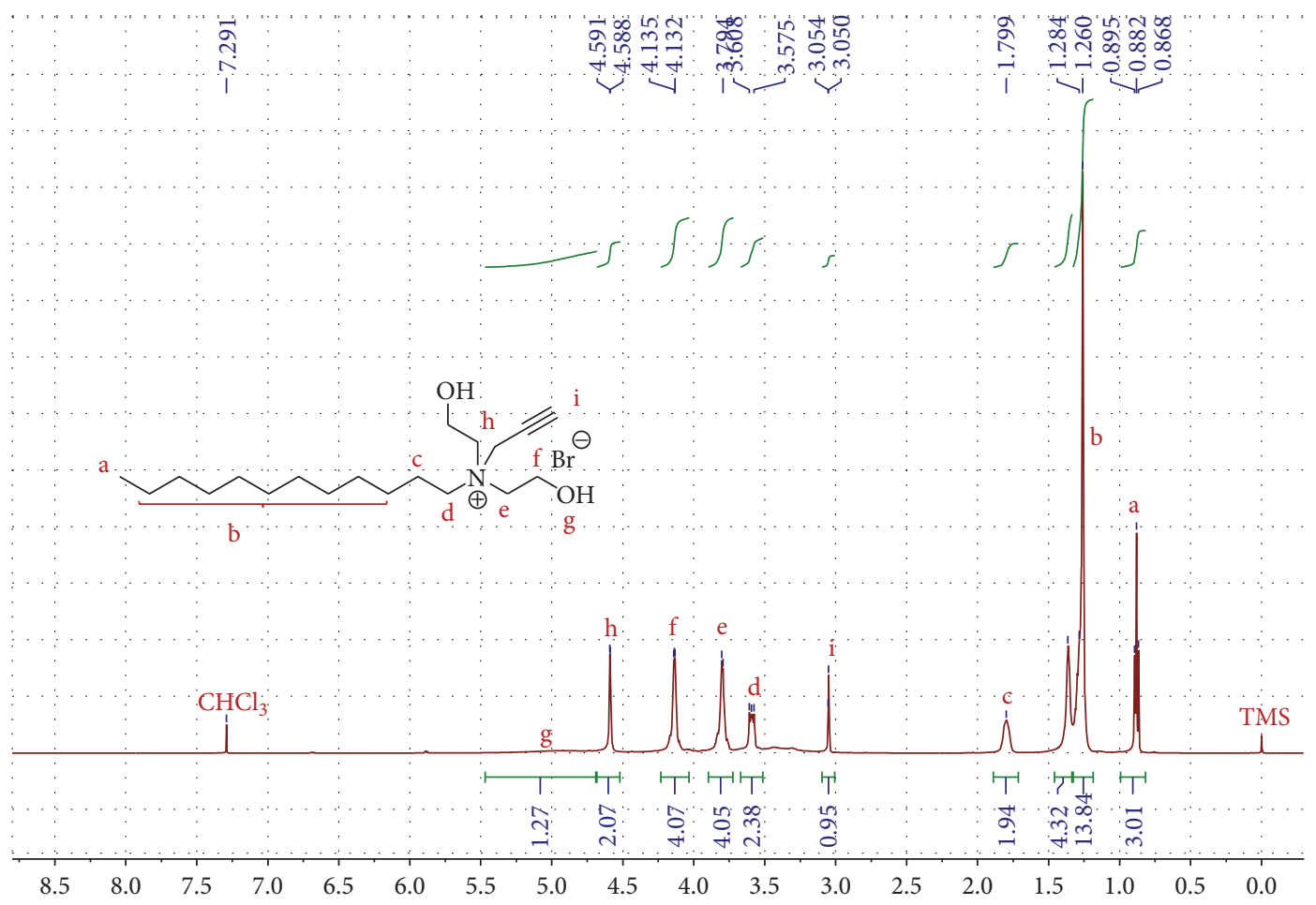

Figure $3:{ }^{1} \mathrm{H}$ NMR spectrum of $2 \mathrm{c}$. 


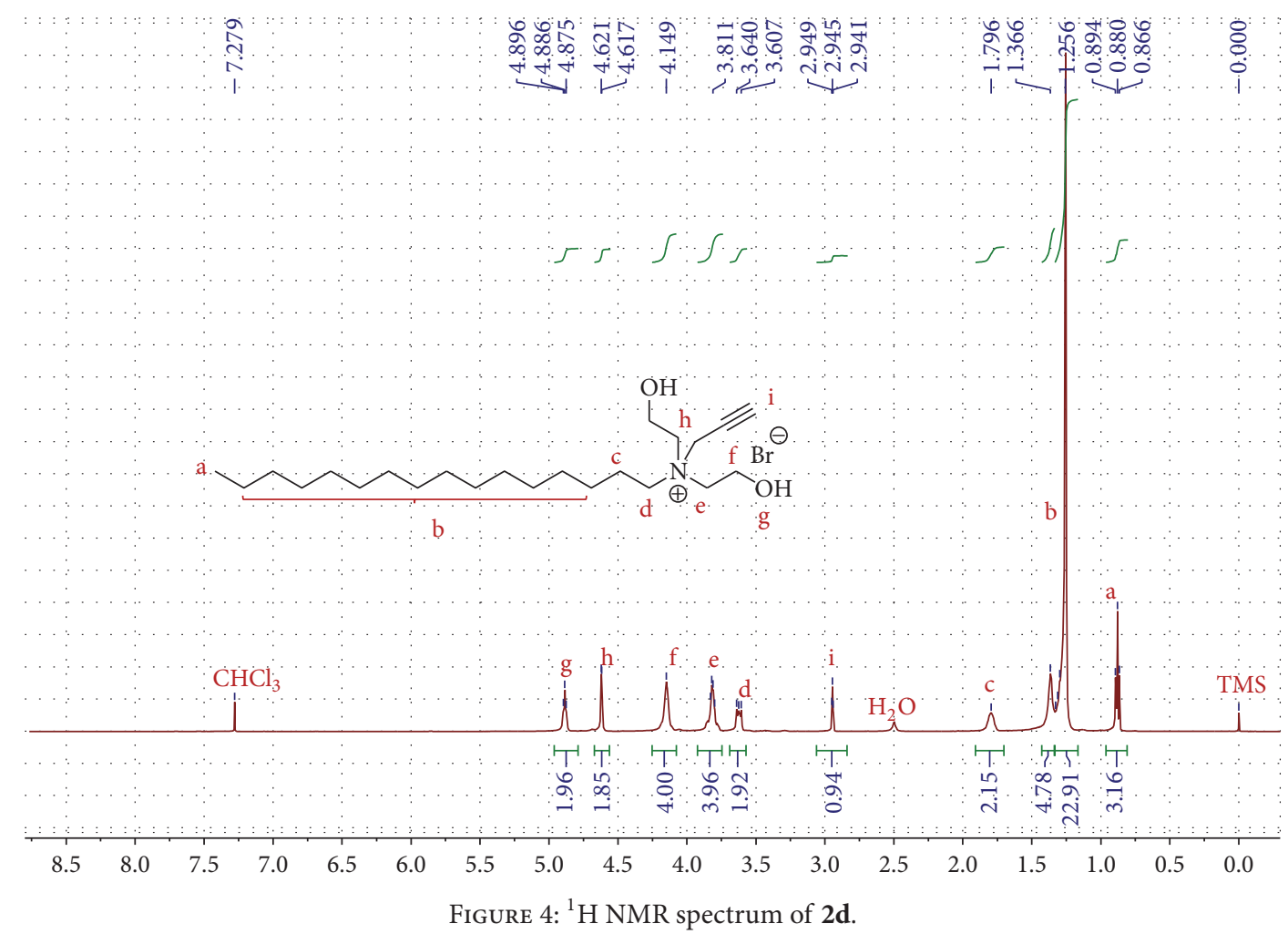

TABLE 1: Surface properties of three surfactants $\mathbf{2 b}-\mathbf{2 d}$.

\begin{tabular}{lccccc}
\hline Surfactants & $\begin{array}{c}\mathrm{CMC} \times 10^{-3} \\
\left(\mathrm{~mol} \mathrm{~L}^{-1}\right)\end{array}$ & $\begin{array}{c}\gamma_{\mathrm{CMC}} \\
\left(\mathrm{mN} \mathrm{m}^{-1}\right)\end{array}$ & $\begin{array}{c}\pi_{\mathrm{CMC}} \\
\left(\mathrm{m} \mathrm{m} \mathrm{m}^{-1}\right)\end{array}$ & $\begin{array}{c}\Gamma_{\max } \times 10^{6} \\
\left(\mathrm{~mol} \mathrm{~m}^{-2}\right)\end{array}$ & $\begin{array}{c}A_{\min } \\
\left(\mathrm{nm}^{2}\right)\end{array}$ \\
\hline 2b & 97.4 & 32.63 & 39.37 & 0.88 & 1.89 \\
2c & 0.763 & 31.83 & 40.17 & 1.47 & 1.13 \\
2d & 0.123 & 31.69 & 40.31 & 1.50 & 1.10 \\
\hline
\end{tabular}

compatibility with VES systems. Because of very short alkyl chain, compound $2 \mathbf{a}$ is too hydrophilic and have not obvious surface activity. Therefore, surface tension was measured only for surfactants $\mathbf{2 b}-\mathbf{2 d}$ at $25^{\circ} \mathrm{C}$. The relationship of surfactants concentration and surface tension is illustrated in Figure 5. Surface tensions of all surfactants decreased by increasing the surfactant concentration until a distinct break at the critical micelle concentration (CMC) is reached. Any further increase in the concentration above CMC has no obvious effect on surface tension.

Surfactants $\mathbf{2 b}, \mathbf{2 c}$, and $\mathbf{2 d}$ attain $\gamma_{\mathrm{CMC}}$ values of 32.63 , 31.83 , and $31.69 \mathrm{mN} / \mathrm{m}$ at $9.74 \times 10^{-2}, 7.63 \times 10^{-4}$, and $1.23 \times$ $10^{-4} \mathrm{~mol} / \mathrm{L}$, respectively (Table 1 ). These results suggested that CMC decreases by increasing the carbon chain lengths while the surface tension at CMC slightly increases [13]. It is worth noting that CMC and corresponding surface tension values are below the same carbon chain lengths known surfactants [14] and may be originated from hydrophobic effects of propargyl group. And yet, the surfactant efficiency to reduce water surface tension $\left(\pi_{\mathrm{CMC}}\right)$, maximum surface access $\left(\Gamma_{\max }\right)$ at the air-water interface, and minimal surface area per molecule $\left(A_{\min }\right)$ at the air-water interface show

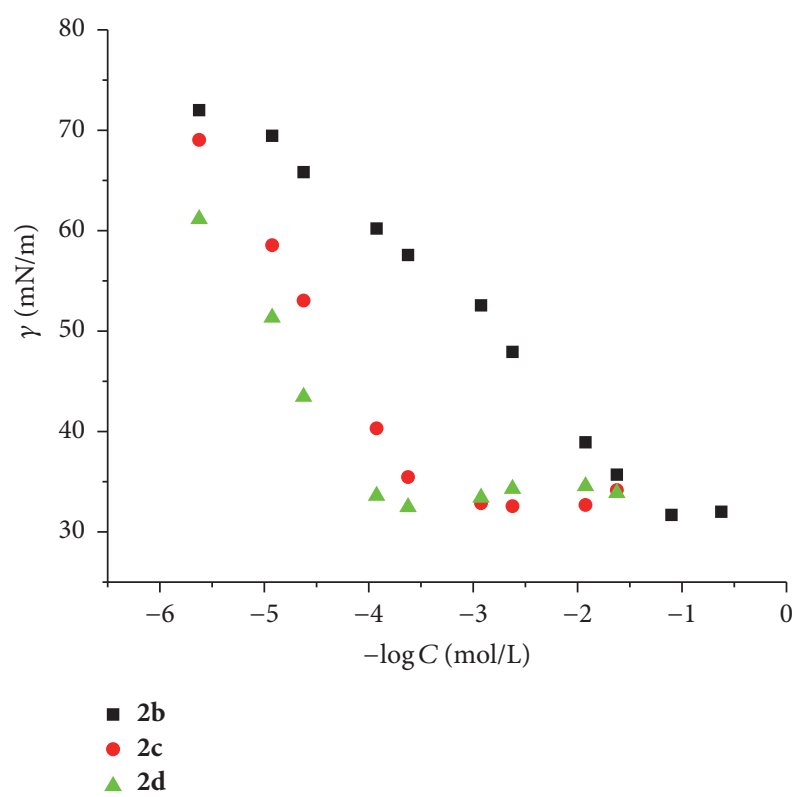

FIGURE 5: Surface tension at various surfactant concentrations of 2b-2d. 
TABLE 2: Weight loss results for $\mathrm{N} 80$ steel in $20 \mathrm{wt} . \% \mathrm{HCl}$ in the absence and presence of inhibitor for $4 \mathrm{~h}$.

\begin{tabular}{|c|c|c|c|c|c|c|}
\hline Entry & Surfactants & $\begin{array}{c}T \\
\left({ }^{\circ} \mathrm{C}\right)\end{array}$ & $\begin{array}{c}c \\
\text { (wt.\%) }\end{array}$ & $\begin{array}{c}V \\
\left(\mathrm{~g} \mathrm{~m}^{-2} \mathrm{~h}^{-1}\right)\end{array}$ & $\theta$ & IE\% \\
\hline (1) & $20 \% \mathrm{HCl}$ & 90 & 0 & 593.8 & & \\
\hline (2) & $20 \% \mathrm{HCl}$ & 60 & 0 & 281.3 & & \\
\hline (3) & $2 a$ & 90 & 1.0 & 46.2 & 0.922 & 92.2 \\
\hline (4) & $2 b$ & 90 & 1.0 & 10.4 & 0.982 & 98.2 \\
\hline (5) & $2 b$ & 60 & 1.0 & 3.75 & 0.982 & 98.2 \\
\hline (6) & $2 c$ & 90 & 1.0 & 17.2 & 0.971 & 97.1 \\
\hline (7) & $2 c$ & 90 & 0.39 & 12.8 & 0.979 & 97.9 \\
\hline (8) & $2 c$ & 90 & 0.10 & 32.4 & 0.945 & 94.5 \\
\hline (9) & $2 c$ & 90 & 0.039 & 59.8 & 0.899 & 89.9 \\
\hline (10) & $2 c$ & 90 & 0.010 & 517.4 & 0.129 & 12.9 \\
\hline (11) & $2 d$ & 90 & 1.0 & 20.7 & 0.965 & 96.5 \\
\hline (12) & $2 e$ & 90 & 1.0 & 163.4 & 0.725 & 72.5 \\
\hline
\end{tabular}

similar trends. The good surface activity of these surfactants leads to potential applications in oil recovery.

3.2. Weight Loss Measurement of $\mathbf{2 a - 2 d}$. The corrosion rate $\left(V_{\text {corr }}\right)$, the inhibition efficiency (IE), and the surface coverage $(\theta)$ are obtained from weight loss measurements of N80 steel in $20 \mathrm{wt} . \% \mathrm{HCl}$ with various concentrations of $\mathbf{2 a - 2 d}$. The results are presented in Table 2 . The percentage inhibition efficiency (IE) and surface coverage $(\theta)$ were calculated using the following equation:

$$
\theta=\mathrm{IE} \%=\frac{V_{0}-V_{\text {corr }}}{V_{0}}
$$

where $V_{0}\left(\mathrm{~g} \mathrm{~m}^{-2} \mathrm{~h}^{-1}\right)$ and $V_{\text {corr }}\left(\mathrm{g} \mathrm{m}^{-2} \mathrm{~h}^{-1}\right)$ were the corrosion rates without and with addition of the corrosion inhibitor, respectively.

As shown in Table 2, it is demonstrated that the synthesized propargyl quaternary ammonium salts were effective in inhibiting the corrosion of N80 steel. Compared with $2 \mathbf{e}$ without a propargyl group, corrosion rate in $\mathbf{2} \mathbf{a}-\mathbf{2} \mathbf{d}$ solutions commonly decreased one to two orders of magnitude (entry (12) versus entries (3), (4), (6), and (11)). It is claimed that alkynyl groups can polymerize on the metal surface, form a protective film on the metal surface, and thus retard corrosion rate [9]. At a relatively high temperature of $90^{\circ} \mathrm{C}$, the inhibition efficiency increased with the inhibitor concentration (entries (6)-(10)). The highest inhibition efficiency of about 97.9\% was achieved at a concentration of 0.39 wt.\% using 2c (entry (7)). Considering the acid concentration and temperature, this inhibition efficiency value is rather favorable. For example, N-benzylquinolinium chloride (BQC), a most commonly used corrosion inhibitor, still has a corrosion rate of $232.68 \mathrm{~g} \mathrm{~m}^{-2} \mathrm{~h}^{-1}$ at the concentration of $1.9 \mathrm{wt} . \%$ [15], which is ten times more than $2 \mathrm{c}$ (entry (6)). But when the concentration of quaternary ammonium salts is below $0.01 \mathrm{wt} . \%$, negligible inhibition efficiencies are found (entry (10)). It indicated that there is a concentration threshold for good corrosion protection. Besides, the effect of the hydrophobic

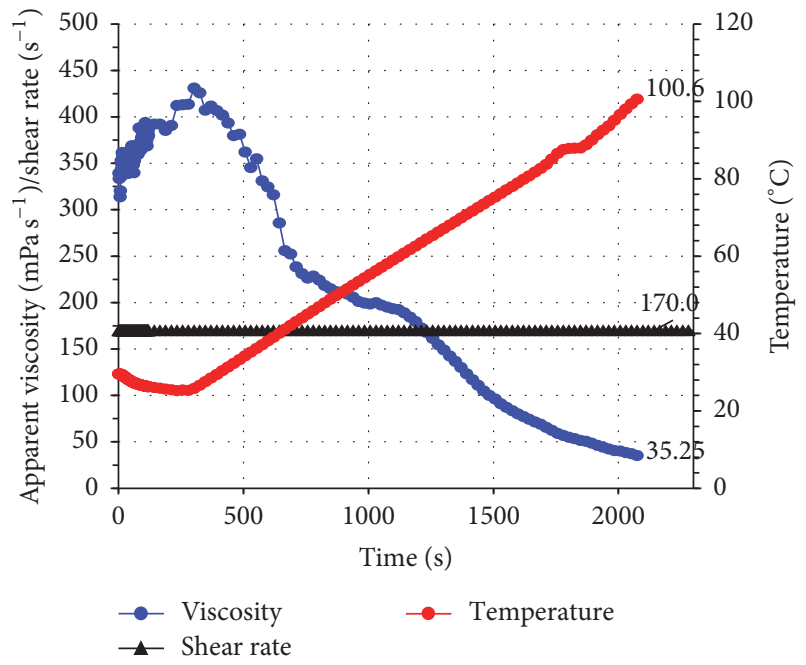

FIGURE 6: The apparent viscosity of 4 wt.\% of surfactant 2 d with $0.36 \% \mathrm{NaSal}$ under steady shear rates $170 \mathrm{~s}^{-1}$.

chain in quaternary ammonium salts on corrosion behavior can be concluded. The corrosion rate follows the sequence $\mathbf{2 b}$ $<\mathbf{2 c}<\mathbf{2 d}<\mathbf{2 a}$ (entries (3), (4), (6), and (11)), indicating that the inhibitory effect decreased gradually with the increase of the length of the hydrophobic chain except $2 \mathbf{a}$. The high hydrophilicity of $\mathbf{2 a}$ may account for this exception. As the temperature increases from $60^{\circ} \mathrm{C}$ to $90^{\circ} \mathrm{C}$, the inhibition efficiency of $\mathbf{2 b}$ almost keeps constant (entries (4) and (5)), which may imply strong absorption of inhibitor molecules.

3.3. Rheological Measurements. Figure 6 shows the apparent viscosity of $\mathbf{2 d}$ at a shear rate of $170 \mathrm{~s}^{-1}$ as a function of temperature. The data show that $\mathbf{2} \mathbf{d}$ can be used as a viscoelastic surfactant. The viscosity increased and reached a maximum in $5 \mathrm{~min}$ and then gradually decreased. As we know, association of viscoelastic surfactant molecules can form wormlike micelles [16]. The entangled wormlike micelles will increase the viscosity of fluids like polymer. The initial increase of 
the viscosity is supposed to be due to the shearing induced growth of the wormlike micelles until reaching a maximum (Figure 6, [17]). Then the viscosity decreases with temperature, and it suggests that micellar networks are gradually broken upon heating [18]. However, until the temperature rises to $100^{\circ} \mathrm{C}$, the viscosity is still more than $25 \mathrm{mPa} \mathrm{s}^{-1}$, which is considered as the standard viscosity of suspending sand [19]. The results indicate these cationic surfactants can be potentially used at relative higher temperature. The trend in viscosity was noted for different types of viscoelastic surfactants [20, 21].

The viscoelastic surfactants own good viscosity and elasticity and thus can be used in fracturing for suspending sands. The fluid composes small molecules and has no residue left in reservoirs after fracturing. Hence, the conductivity is very high with no formation damage [16]. Moreover, viscoelastic surfactant was also found useful to self-diverting-acid fracturing application. The viscoelasticity of solution does not develop until the acid reacts with carbonate in the formation (in this article, we use sodium salicylate to produce gel). The increases in $\mathrm{Ca}^{2+}$ ions and $\mathrm{pH}$ due to the $\mathrm{HCl}$-carbonate reaction caused in situ gelling of the acid [22]. The high viscosity temporarily blocks the wormholes formed in the rock matrix, allowing the acid to cover the unacidized area.

\section{Conclusion}

Four alkyl propargyl bis(hydroxyethyl) ammonium surfactants with different lengths in hydrophobic tail were high yield synthesized by following an efficient method from commercially available chemicals. Structures of the synthesized surfactants were characterized by ${ }^{1} \mathrm{H}$ NMR. Surface tension, corrosion inhibition efficiency, and apparent viscosity were evaluated. The results indicate these surfactants exhibit excellent surface properties. The critical micelle concentration (CMC) values of the surfactants $\mathbf{2 c}$ and $\mathbf{2 d}$ were found to be $7.63 \times 10^{-4}$ and $1.23 \times 10^{-4} \mathrm{~mol} / \mathrm{L}$, and the corresponding surface tension $\left(\gamma_{\mathrm{CMC}}\right)$ values were 31.83 and $31.69 \mathrm{mN} / \mathrm{m}$, respectively. Furthermore, all propargyl quaternary ammonium salts were effective in inhibiting the corrosion of N80 steel. They can be used at a relatively high temperature $\left(90^{\circ} \mathrm{C}\right)$ and at a concentration as low as 0.039 wt.\%. In addition, the apparent viscosity of surfactant $\mathbf{2 d}$ was studied at various temperatures, and it can be used as a viscoelastic surfactant up to $100^{\circ} \mathrm{C}$. The unique surface-active, corrosion protection abilities, thermal stability, and viscoelastic properties of these surfactants make them strong candidates for various oilfield applications.

\section{Conflicts of Interest}

The authors declare no financial conflicts of interest.

\section{Acknowledgments}

This research was financially supported by PetroChina Innovation Foundation (Grant no. 2016D-5007-0205) and the Science Foundation of China University of Petroleum, Beijing (Grant no. 2462015YJRC027).

\section{References}

[1] M. J. Economides and T. Martin, Modern Fracturing: Enhancing Natural Gas Production, ET Publishing, Houston, Tex, USA, 2007.

[2] W. Al-Sadat, M. S. Nasser, F. Chang, H. A. Nasr-El-Din, and I. A. Hussein, "Rheology of a viscoelastic zwitterionic surfactant used in acid stimulation: Effects of surfactant and electrolyte concentration," Journal of Petroleum Science and Engineering, vol. 124, pp. 341-349, 2014.

[3] F. F. Chang, A. M. Acock, A. Geoghagan, and P. T. Huckabee, "Experience in acid diversion in high permeability deep water formations using visco-elastic-surfactant," in Proceedings of the 2001 SPE Annual Technical Conference and Exhibition, Society of Petroleum Engineers, October 2001.

[4] D. Taylor, P. S. Kumar, D. Fu et al., "Viscoelastic surfactant based self-diverting acid for enhanced stimulation in carbonate reservoirs," in Proceedings of the SPE European Formation Damage Conference, 2003.

[5] G. Daccord, R. Lenormand, and O. Liétard, "Chemical dissolution of a porous medium by a reactive fluid-I. Model for the "wormholing" phenomenon," Chemical Engineering Science, vol. 48, no. 1, pp. 169-178, 1993.

[6] H. A. Nasr-El-Din, A. H. Al-Ghamdi, A. A. Al-Qahtani, and M. M. Samuel, "Impact of acid additives on the rheological properties of a viscoelastic surfactant and their influence on field application," SPE Journal, vol. 13, no. 01, pp. 35-47, 2008.

[7] M. Finšgar and J. Jackson, "Application of corrosion inhibitors for steels in acidic media for the oil and gas industry: a review," Corrosion Science, vol. 86, pp. 17-41, 2014.

[8] M. A. Quraishi and D. Jamal, "Corrosion inhibition of N-80 steel and mild steel in $15 \%$ boiling hydrochloric acid by a triazole compound-SAHMT," Materials Chemistry and Physics, vol. 68, no. 1-3, pp. 283-287, 2001.

[9] E. Barmatov, J. Geddes, T. Hughes, and M. Nagl, "Research on corrosion inhibitors for acid stimulation," in CORROSION 2012, NACE International.

[10] K. Dan and S. Ghosh, "PH-responsive aggregation of amphiphilic glyco-homopolymer," Macromolecular Rapid Communications, vol. 33, no. 2, pp. 127-132, 2012.

[11] Q. Ge, J. Ran, J. Miao, Z. Yang, and T. Xu, "Click chemistry finds its way in constructing an ionic highway in anion-exchange membrane," ACS Applied Materials and Interfaces, vol. 7, no. 51, pp. 28545-28553, 2015.

[12] Y. Zhang, D. Zhou, and Y. Feng, "In-situ formation of viscoelastic wormlike micelles in mixtures of non-surface-active compounds," Journal of Surfactants and Detergents, vol. 18, no. 1, pp. 189-198, 2015.

[13] Z. Han, X. Yang, Y. Liu, J. Wang, and Y. Gao, "Physicochemical properties and phase behavior of didecyldimethylammonium chloride/alkyl polyglycoside surfactant mixtures," Journal of Surfactants and Detergents, vol. 18, no. 4, pp. 641-649, 2015.

[14] A.-A. M. A. Omar and N. A. Abdel-Khalek, "Surface and thermodynamic parameters of some cationic surfactants," Journal of Chemical and Engineering Data, vol. 43, no. 1, pp. 117-120, 1998.

[15] Z. Yang, F. Zhan, Y. Pan et al., "Structure of a novel Benzyl Quinolinium Chloride derivative and its effective corrosion inhibition in 15wt.\% hydrochloric acid," Corrosion Science, vol. 99, pp. 281-294, 2015.

[16] J. Yang, "Viscoelastic wormlike micelles and their applications," Current Opinion in Colloid and Interface Science, vol. 7, no. 5-6, pp. 276-281, 2002. 
[17] R. Gamez-Corrales, J.-F. Berret, L. M. Walker, and J. Oberdisse, "Shear-thickening dilute surfactant solutions: Equilibrium structure as studied by small-angle neutron scattering," Langmuir, vol. 15, no. 20, pp. 6755-6763, 1999.

[18] S. Ezrahi, E. Tuval, and A. Aserin, "Properties, main applications and perspectives of worm micelles," Advances in Colloid and Interface Science, vol. 128-130, pp. 77-102, 2006.

[19] E. Pitoni, G. Burrafato, F. Devia, and N. Heitmann, "Polymerfree fracturing fluid revives shut-in well," World Oil, vol. 220, no. 9, pp. 77-82, 1999.

[20] W. Nehmer, "Viscoelastic Gravel-Pack Carrier Fluid," in Proceedings of the SPE Formation Damage Control Symposium, Bakersfield, Calif, USA.

[21] J. E. Brown, L. R. King, E. B. Nelson, and S. A. Ali, "Use of a viscoelastic carrier fluid in frac-pack applications," in Proceedings of the SPE Formation Damage Control Symposium, Society of Petroleum Engineers, 1996.

[22] B. Lungwitz, C. Fredd, M. Brady, M. Miller, S. Ali, and K. Hughes, "Diversion and cleanup studies of viscoelastic surfactant-based self-diverting acid," SPE Production and Operations, vol. 22, no. 1, pp. 121-127, 2007. 

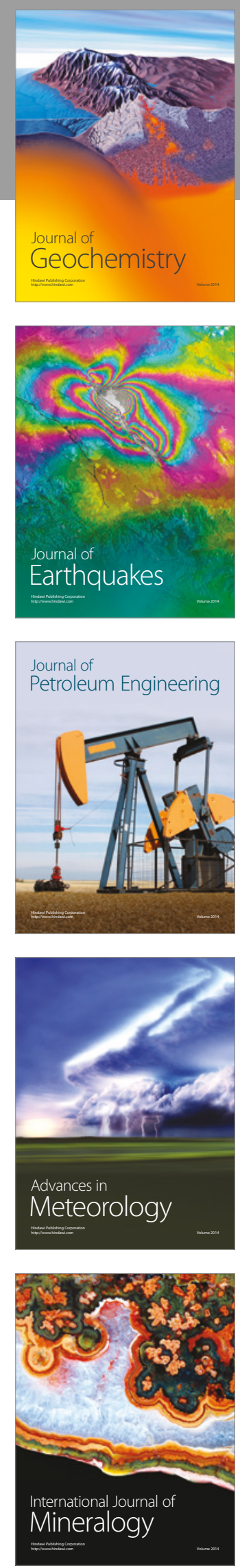
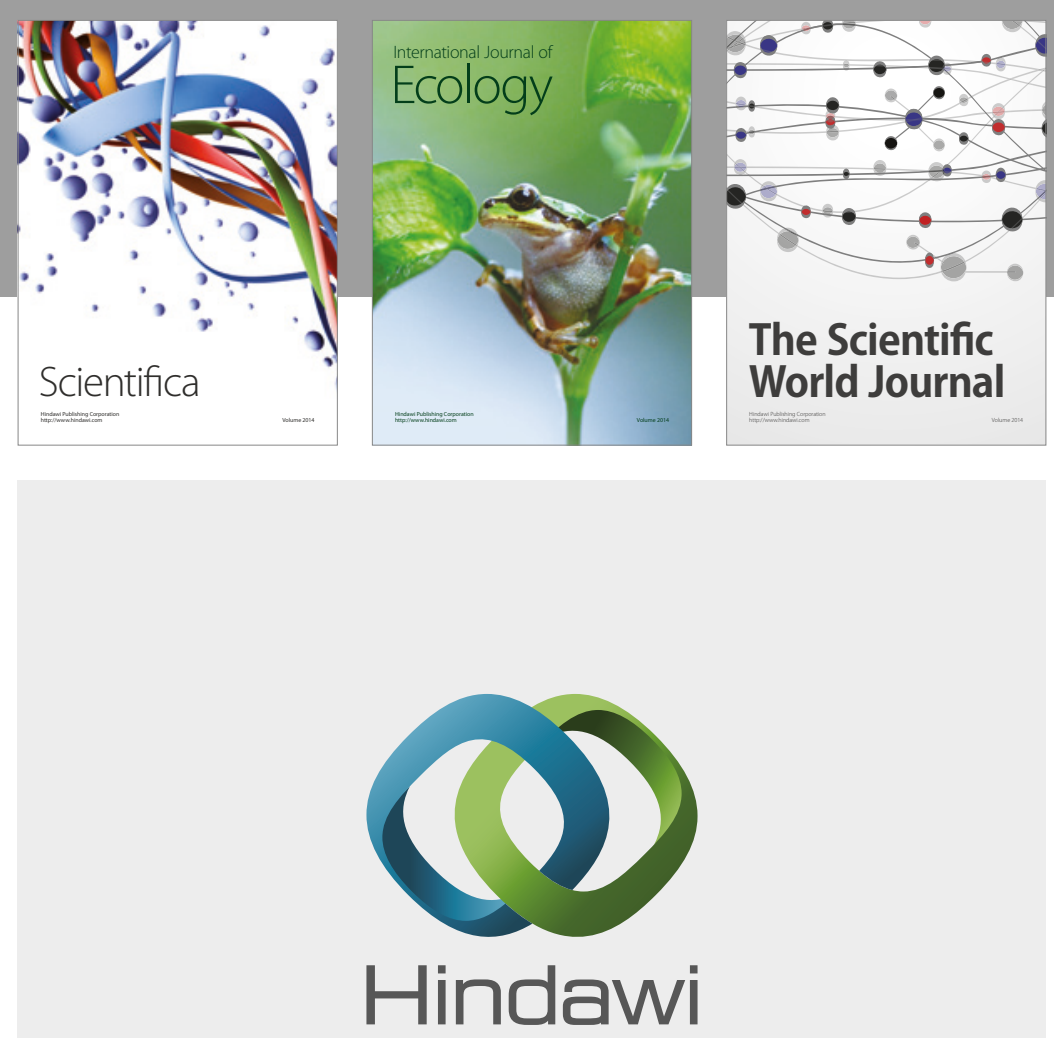

Submit your manuscripts at

https://www.hindawi.com
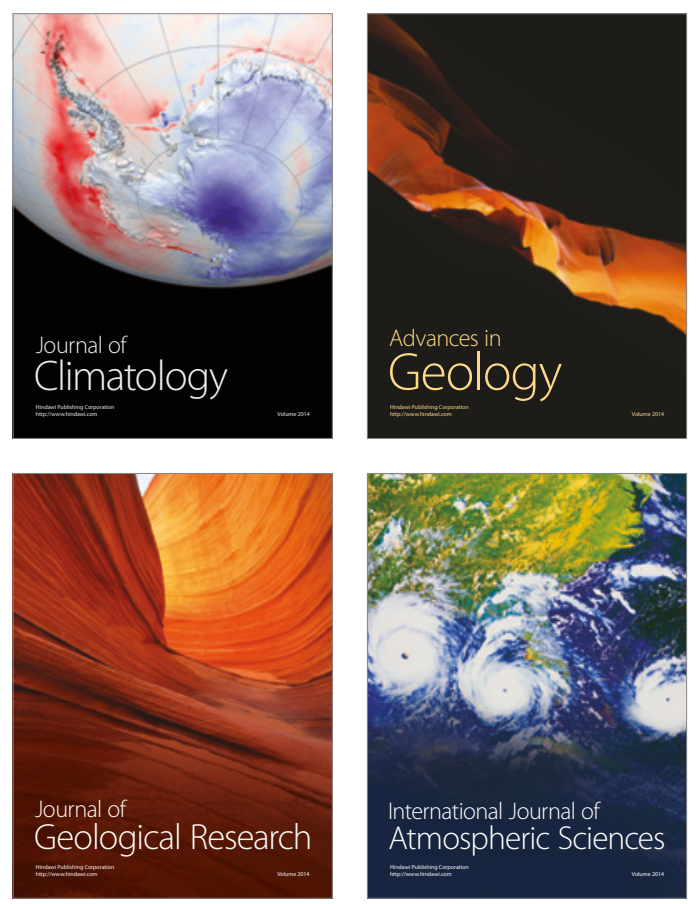

The Scientific

World Journal
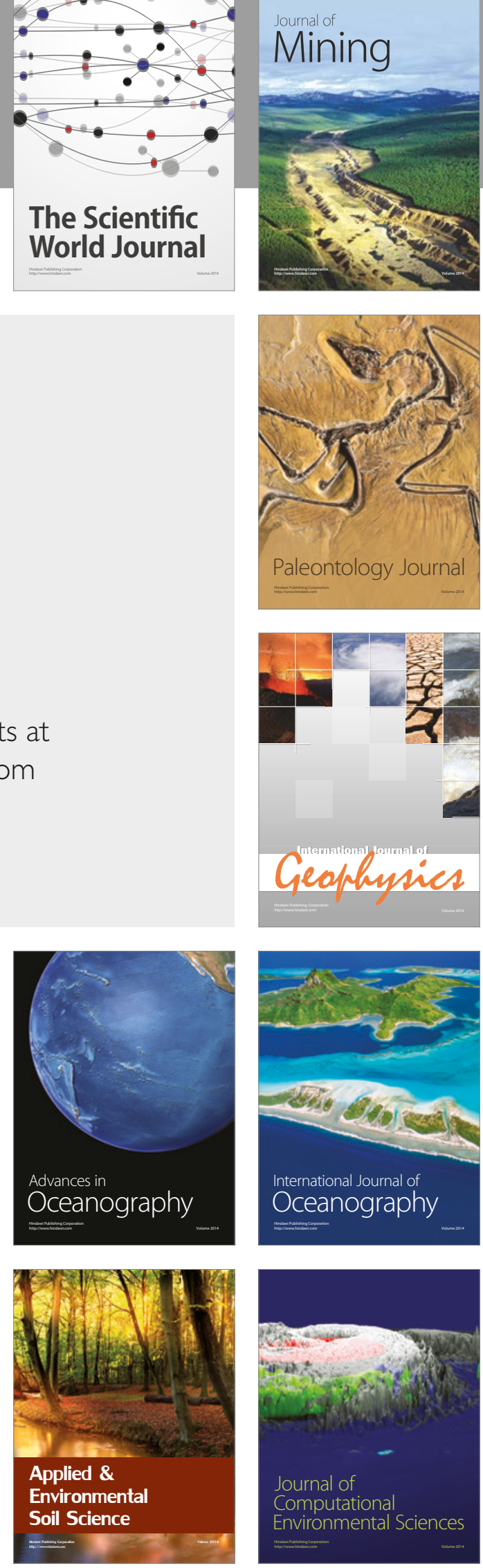